\title{
Continuous Improvement - Development with Time
}

\author{
Mashael Ali Haddas, Mona Hasan Asiri, Reham Faya Mukhalid, Salha Saeed Alahmari, \\ Shatha Ali Al-Qathtani, Syed Hamid Hasan \\ Department of Information Systems \\ Faculty of Computing and IT \\ King Abdulaziz University, Jeddah, Saudi Arabia
}

\begin{abstract}
This paper aims at providing an overview of the evolution, current research and the history of continuous improvement over time through reviewing the literature extensively. The paper covers the inception of continuous improvement and its evolution into today's worlds sophisticated methodologies. The research covers the well known programs of continuous improvement if not covering the entire plethora of the past and the present. It also covers the various tools used by the organizations for addressing the need of continuous improvement and thus may serve the purpose of reference for people who wish to pursue the field of continuous improvement and wants to know its development form its historical form to its modern day avatar. The paper is written in the form of a General review
\end{abstract}

\section{Keywords}

Evolution, TQM, Six Sigma, Lean Production, Quality, Continuous improvement

\section{INTRODUCTION}

Continuous Improvement is defined as ("Bessant et al., 1994") "a company-wide process of focused and continuous incremental innovation" while Deming (Juergensen, 2000) describes Continuous improvement as "Improvement initiatives that increase successes and reduce failures". Still some treat some consider CI as a branch of practices like TQM (Total Quality Management) or for other it is separate from TQM and it a totally new method to achieve excellence in the market and enhance creativity. (Gallagher et al.; 1997, Caffyn, 1999; Oakland, 1999.). Kossoff (1993), claims achievement of total quality can be done through constant persuasion of $\mathrm{CI}$ by all levels in an organization.

Whereas we can describe CI as a We define CI more generally as an ethos in an organization that aims at eliminating all wastage in all processes or systems through sustained improvement. The process makes every individual in the organization its part and does not necessitate capital investment. CI can be the result of a drastic change brought about a change in technology or an innovation or it may be because of a gradual improvement brought over a period of time. Additionally, gradual improvements collectively form major changes in the system. At any level, improvements are results of techniques and tools aimed at searching and minimizing variations, waste and problems.

In the past many aspects of $\mathrm{CI}$ have been studies and researched upon, in this paper we would look into the evolution and history of CI, where it has its modest beginning of sophisticated techniques of Improvement to the current day practices widely used across the world. We would initially discuss the origins of $\mathrm{CI}$, then the CI techniques that have developed over time. We would then cover the different techniques and tools used by organizations for addressing the requirement of improvement. We would also present an overview of the studies done on this topic.

\section{CI - EVOLUTION AND HISTORY}

Beginning of the CI known today can be considered to be from $1800 \mathrm{~s}$ in the form of initiatives taken by various organizations' managements, to encourage improvement driven by employees that were rewarded by incentives ("Schroeder and Robinson, 1991"). The program of National Cash Register introduced opportunities of employee development, reward schemes thus improving the relationship between the management and laborers. Scientific Management gained importance in the late 19th and the early 20th century, that consisted of enabling managers with scientific methodologies to deal with problems of production lines through analysis and solution finding. These measures were carefully constructed through strict time trials for achieving labor standards and appropriate piece costs. "Training within Industry" concept was introduced by the US Govt. during World War II for enhancing the output of the industry at a national level. The concept was based on training of job methods and introduction of CI techniques and it importance to supervisors. The same was later implemented by experts like Gilbreth, Juran and Deming in Japan along with US forces there at the end of World War II (Robinson, 1990). Later on the Japanese established indigenous concepts of quality control, which were initially used for manufacturing, but eventually transformed into a complete tool of management for continual improvement that involves the entire organization at all levels. (Imai, 1986).

The earlier CI methodologies were specific to improvement in work, whereas the modern principles of CI are pertinent to methodologies that are comprehensive and organized. The new methods associate almost the entire organizations with themselves and led to introducing the popular TQM concepts, which were made popular by Edward Deming in Japan as well.

\section{CI TECHNIQUES}

With the passage of time it organizations have required large scale continuous improvement, this lead to development of CI technologies that were based on Process and/or quality improvement so that the quality is improved, production line is simplified and waste reduced. The most famous of them are: lean six sigma, balanced scorecard, six sigma, and lean manufacturing.

\subsection{Balanced Scorecard}

In the last decade of the 20th century David Norton and Robert Kaplan introduced a technique that could convert the organization's objective into, initiatives, goals and measures related to four aspects i.e. Learning \& Growth, internal business process, customer and financial. The technique was given the name of balanced scorecard. This scorecard is in general used for clarification of business strategy, linking the annual budgets to the organization's objectives, allowing change, increasing the understanding of the mission statements and vison of the company throughout the 
company. The balanced scorecard translates the vision and mission of an organization into quantifiable and appraisable measures of performance and objectives so that it can be identified if the desired result has been achieved by the management. Almost half $(50 \%)$ of the Fortune-1K companies have adopted the balanced scorecard technique (Kaplan and Norton, 1996). Balanced scorecards have been defined as a combination of Communication tools, Strategic Management systems and measurement systems (Niven, 2002):

1. Communication tools. The strategy of the organization is described by Balanced Scorecard to the common employees with clarifications required. The employees can further contribute to the overall progress of the organization once they are made aware of the strategies (Niven, 2002).

2. Strategic management systems. The shortterm actions of the organization are aligned with the strategy of the organization with the help of balanced scorecard. This aids in removal of hindrances to the strategic implementation of the organizations in the long term.

3. Measurement systems. Gaplin(1997) stressed "measurable goals and objectives" to be critical factors in making a strategy successful. The balanced scorecard makes it possible for converting the strategy and vision of an organization into measures and objectives instead of emphasizing solely on financial measures that are of little help.

According to Deming the traditional methods of quality assurance that inspected a product after manufacture were not capable of finding the cause of the variation that were present through the entire process of production. The need of considering all the business process and having feedback loops for all of them was highlighted by him, in order to achieve improvement. Feedback in considered in the strategy outputs along with the process outputs in the balanced scorecards. The emphasis must be laid on selecting processes that can be successfully implemented for the strategy of the organization to be successful, instead of mere improvement in the current process's performance. The balanced scorecard provide tools to managers for evaluating performance and the different kind of feedback considered provide the necessary guidance for improving continuously.

\subsection{Six Sigma}

In the recent past the introduction of Six Sigma by Motorola Inc., in 1986 for using Statistical process control to measure process quality, made it popular in the USA. It was mission of considerably improving products and services in a 5 year period by Motorola. For that Motorola launched Six Sigma in 1987. "Linderman et al., 2003" defined Six Sigma as "an organized and systematic method for strategic process improvement and new product and service development that relies on statistical methods and the scientific method to make dramatic reductions in the customer defined defect rates". The core of the technique was to minimize defects closest to Zero along with reduction in variations across the organization's processes. The DMAIC model found its development for this reason. Where " $\mathrm{D}=$ define opportunities", " $\mathrm{M}=$ measure performance", " $\mathrm{A}=$ analyze opportunities", "I=improve performance", and " $\mathrm{C}=$ control performance" (DAMIAC). The quality measurements provided by Six sigma can be applied to Service areas, Administration, and design along with manufacturing.
Astonishing results were obtained between 1987 - 1997 by Six sigma application in Motorola. A USD 15 Billion saving was made and $5 x$ growth was achieved by sales team during this time ("Klefsjo" et al., 2001"). Even the small and midsized firms consider it mission critical and a best practice to have investments made in six sigma. Six sigma was used by companies to achieve $100 \mathrm{x}$ improvement in a short 5-year span using the Six sigma methodology. After Motorola Six Sigma has been used by organizations like Ford, Honda, Sony, Honeywell, ABB and GE for achieving excellence in Business.

\subsection{Lean Manufacturing}

In the early 1800 s lean manufacturing was systemized by Henry Ford, by establishing a mass production concept in the factories of Ford Motors. This concept was adopted and improved upon by the Japanese. Under this methodology waste is eliminated by identifying an approach that is systematic, by using CI.

Quality Circles were established by Toyota inside the production process, in 1950s. At the end of World War II, the Exec. VP of Toyota, Taiichi Ohno, was assigned the responsibility to develop a production system that was efficient in manufacturing automobiles. This lead to the development of the renowned TPS (Toyota Production System) that was based on the assembly lines of Ford motors, after customization of the process and production for the low requirement car sectors of Japan. The TPS is also called Lean Manufacturing and is a widely used phenomena worldwide("Womack et al., 1990"). Product flow is maintained continuously to the factory so that the demand changes are adjusted flexibly, under a methodology. This form of product flow is called JIT(Just in Time) production, that utilizes systematic techniques for reducing inventory and scrap, in fact all kinds of waste. It leads to reduced costs and increase in productivity and quality.

The core idea behind lean manufacturing is eliminating waste in all the production areas that include factory management, supplier networks, product design, and customer relations. Lean thinking is described by "Womack and Jones 1996" as Muda's "antidote" which means waste in Japan. The goal of lean manufacturing is to produce high quality product most economically by reducing space between orders, time to produce, inventory and human effort. The definition of Waste is any component of the product that the customer is unwilling to pay for. After proper application of Lean manufacturing organizations are able to learn. It also leads to non-repetition of mistakes, as mistakes are another kind of waste which the lean manufacturing aims to eliminate ("Robinson, 1990"). Anything not adding to process value is eliminated by lean toolbox. Womack and Jones conducted a study that manufacturers in Japan are two times more effective than manufacturers in USA and the west. It was determined by them that the 3 basic lean manufacturing principles are: Organization's commitment to CI, Customer Pull oriented focus and improved flow of information and material throughout the business. ("Womack et al., 1990; Womack and Jones, 1996").

\section{EXISTING RESEARCH}

We do not find any theoretical origin of CI in literature (Savolainen, 1998). However CI seems to have obtained its qualities from the other initiatives of quality like Lean Manufacturing and TQM. Even though research has been done in the field of CI ("Bessant et al., 1994; Bessant and 
Caffyn, 1997"), according to "Gilmore, 1999" more research covering other aspects of $\mathrm{CI}$ is required.

"Lillrank and Kano 1989" define CI as the "Principal of Improvement", yet Kaizen( Japanese for CI) is not defined by the literature from JUSE(Japanese Union for Scientists \& Engineers), it is however used for defining other concepts. Even though CI and Kaizen are considered interchangeable, Imai, 1986 describes 3 categories of Kaizen: Individual oriented, Group oriented and Management oriented Kaizen. Individual-kaizen derives its roots from bottom-up strategy, where the solution to a problem is recommended by the worker. It has proved to be quite successful in the industry in Japan, as the worker is best suited to know the solution to an existing issue because of his presence on the shop floor. Some organizations have even declared incentives based on the nature of the issue and the solution suggested, this encourages the employees to keep a lookout for the problem areas and suggesting suitable solutions for them. The best examples of Group-kaizen is a quality circle, in which the employees form teams for identifying issues that occur in the daily activities and suggesting their solutions, without the management having any hand in it. The most important of the three is Management-kaizen as it has its focus on the companies' strategy and require involvement of all.

A close link between $\mathrm{CI}$ and quality was found by "Jha et al. 1996" after examining the existing literature. Quality's and CI's link is explained by "Berger 1996", such that CI "should rightfully be regarded as a general development perspective, applicable with or without the context of TQM". TQC (Total Quality Control) was defined by Imai (1986) as "organized kaizen activities involving everyone in a company- managers and workers, in a totally integrated effort toward improving performance at every level". Yet, based on the association of quality with CI, by a considerable number of scholars, the fact that CI aims at improving things; there appears to a link existing between the two.

The initial development of CI was in organizations that had processes that were repetitive and product based, thus they has high level of standardization of processes and products. There were special teams constituted for improving tasks separate from the regular tasks in the organizations. It was suggested by "Berger 1997" that the regular and the improvement tasks can be combined into daily work of the employees, and based on the process choice and product design, CI should comply with the level of involved standardization. Thus different work environments can use CI programs. We would now present an organizational design topology that is two dimensional:

1. "Basic task" design (in which design the two dimensions are Group and individual task.), and

2. Improvement task (integrated vs parallel).

The "Basic task" is related to product standardization and work process: under this design strategy, the group task are introduced in areas where low level of standardization is required, whereas for high product standardization the individual task design is used.

Production systems with high degree of standardized have the improvement tasks assigned to individual professional like quality or engineering experts in improvement. While for low degree standardization production systems, common employees are assigned the task of improvement as part of their group tasks. Under the parallel dimension strategy the improvement tasks are assigned in "parallel" to the existing tasks but the improvement task are separate category altogether. Under the "integrated" dimension the improvement tasks are amalgamated into the regular work activities of the employees.

The two dimensional approach prompted Berger to present 5 organizational designs:

A. Individual CI: Suggestions systems form the improvement systems that are primarily initiated by the individuals. The task of the individual is to suggest whereas the experts take up the implementation part.

B. CI through Expert taskforce: The CI is brought about by short term teams of experts in the fields of maintenance, engineering and quality thus considerable investment and time is required for the improvement tasks.

C. Organic CI: Improvement activities are carried out by multifunctional workgroups. The fact that no experts are involved in the planning and design of the tasks and the decisions are made within the group only, separates Organic CI from any modes of CI.

D. Wide-focus CI: This design combines the Expert Taskforce and the Organic CI. It is for CI in independent workgroups over a short span of time where the CI processes teams are combined.

E. Quality-control circle: This format has a group of employees assigned the task of improvement who have regular meetings for discussion of issues pertinent to quality and they try find solutions to the quality issues faced.

CI applicability in various organization types was studies by "Lindberg \& Berger 1997". They discovered successful integration of CI into daily activities by a number of Swedish firms where low degrees of standardization of processes and product was required. The core idea was to highlight the fact that in Japan, Kaizen activities followed a parallel model of task assignment where $\mathrm{CI}$ and regular tasks were kept separate and run in parallel, which was in contrast them being integrated in Sweden. Even though the parallel design has its advantage of inter-department partnership, yet it has high costs of administration associated with it ("Krishnan et al., 1993”).

CENTRIM the model for measuring the CI capability ("Bessant and Caffyn, 1997"), was introduced in the Brighton University, UK. It provides strong tools for measuring the effectiveness of the CI implementation. The research presented behaviors and routines that needed to be implemented for CI to be successful, along with certain characteristics that an organization must have to be $\mathrm{CI}$ capable. "Caffyn, 1999", defined CI capability as "the ability of an organization to gain strategic advantage by extending involvement in innovation to a significant proportion of its members". The CI capability consists of 10 generic behaviors that an organization must possess, irrespective of its size:

1. During the course of the everyday work the employees share a set of cultural values that reinforce $\mathrm{CI}$;

2. Capturing and deployment of the learning amassed both by groups and individuals is done; 
3. Learning is based on negative and positive experiences of self and others;

4. Work effectiveness is present across boundariesexternal and internal, at all levels;

5. Proactive engagement in incremental improvement is done by people across the organization;

6. Commitment to participation and leading of CI is displayed by the managers at all tiers;

7. Support and reinforcement of the CI mechanisms and approaches like Procedures, systems and organizations' structure is assessed regularly;

8. Development and monitoring of mechanisms like teamwork and training are used for is encouraging employee involvement in CI;

9. Improvement activity is prioritized along with focusing on the objectives and strategic goals of the organization by the individual groups;

10. Understanding and awareness of the companies' objectives and aims are demonstrated by the employees;

There is a possibility that organizations may face a difficult time in practicing some of the above behaviors as employees would not be very willing to shed the traditional mindset and adapt the new thought process. Yet, for sustaining these behaviors among the employees, certain enablers are warranted by the CI model: Company policies and procedures, recognition systems and facilitators etc. They would encourage the above behaviors, however these enablers would be developed over time and need to be monitored.

It is highlighted by "Jha et al. 1996" that understanding of CI's contributions to the organizations' strategy and mission promotes the success rate. A distinct element of CI that is centered on problem solving was also discovered by them. They also suggested use of problem solving techniques such as Performance monitoring, work simplification and work processes etc.

In the end, in relation to the comprehensive methodologies of CI Finally, a framework was proposed by "Khusrow, 2001" that compared the various Improvement techniques, it was deduced by him that the best CI program is Lean manufacturing for all the researched industries. However, his research was specific to the domain of Aerospace and if other domain were included in the research there would have been different, as the requirements and challenges of each domain are specific to its own kind.

\subsection{Discussion}

The CI program has its applicability to a vide variety of organizations. The managers in the organizations are required to assess level of standardization required, process choice and product design for the organization to choose the most suited methodology for having a successful CI implementation in the organization. The usefulness and effectiveness of the CI techniques can be determined by monitoring the behaviors and routines that are termed vital for successful CI implementation. There is no doubt that CI is accompanies with struggles and hardships and cannot be achieved without the active and constant participation across the organization, including the providing of the necessary support and resources by the top managers. Without the above we cannot have a successful CI implementation.

\section{CONCLUSION}

The paper traced the development of CI, starting from its humble beginnings in manufacturing industry to its more sophisticated avatars, consisting of high performance tools of improvement, which can be applied to any organization. The present research work highlights that even though CI has its numerous virtues, yet for having a successful implementation of the CI methodologies and achieving the desired results, organizations need to make changes at a number of levels and facets. There is also a general agreement that quality management tools and CI programs go together as both of them aim at achieving progress, growth and success through improvement.

The current work can be used by researchers and CI Practitioners as a point of reference while choosing a methodology or CI program. The researchers would be able to refer to the history of development and evolution of CI and its current status. The practitioners would find valuable techniques, tools, methods and principles used in CI programs in this paper.

Even though we have seen ample research work being done on the distinct CI techniques and there has been development of quite a few tools that can be used for evaluating CI effectiveness, yet we do not have knowledge of research work being conducted on designing a guideline or framework that would enable an organization to select the most appropriate CI technique suitable for the organization, within the budgetary constraints. Hence, mechanisms for determining which CI technique would be appropriate for an organization needs to be studied. The specific tools and methodology required for successful implementation of the selected CI techniques should also be able to be identified by this mechanism.

\section{ACKNOWLEDGMENTS}

The authors also, acknowledge with thanks Department of Information Systems-Faculty of Computing and Information Technology and Science and Technology Unit, King Abdulaziz University for extending all support and facilities in completing this paper.

\section{REFERENCES}

[1] Gaplin, T. (1997), Making Strategy Work, Jossey-Bass, San Francisco, CA

[2] George, M. (2002), Lean Six Sigma: Combining Six Sigma Quality with Lean Production Speed, McGrawHill, New York, NY.

[3] Gilmore, H. (1999), "Continuous incremental improvement: an operations strategy for higher quality, lower costs, and global competitiveness", in Costin, $\mathrm{H}$. (Ed.), Strategies for Quality Improvement, The Dryden Press, Hinsdale, IL, pp. 47-55.

[4] Imai, M. (1986), Kaizen: The Key to Japan's Competitive Success, Random House, New York, NY.

[5] Jha, S., Michela, J. and Noori, H. (1996), "The dynamics of continuous improvement: aligning organizational attributes and activities for quality and productivity", International Journal of Quality Science, Vol. 1 No. 1 , pp. 19-47.

[6] Juergensen, T. (2000), Continuous Improvement: Mindsets, Capability, Process, Tools and Results, The Juergensen Consulting Group, Inc., Indianapolis, IN. 
[7] Kaplan, R. and Norton, D. (1996), The Balanced Scorecard: Translating Strategy into Action, Harvard Business School Press, Cambridge, MA.

[8] Khusrow, U. (2001), "Development of a framework for comparing performance improvement programs", $\mathrm{PhD}$ thesis, Massachusetts Institute of Technology, Cambridge, MA.

[9] Klefsjo", B., Wiklund, H. and Edgeman, R. (2001), "Six sigma as a methodology for total quality management", Measuring Business Excellence, Vol. 5 No. 1, pp. 31-5.

[10] Kossoff, L. (1993), “Total quality or total chaos?”, HR Magazine, Vol. 38 No. 4, pp. 131-4.

[11] Krishnan, R., Shani, A., Grant, R. and Baer, R. (1993), "In search of quality improvement:problems of design and implementation", Academy of Management Executive, Vol. 7 No. 4, pp. 7-20.

[12] Lillrank, P. and Kano, N. (1989), Continuous Improvement: Quality Control Circles in Japanese Industry, Center for Japanese Studies, University of Michigan, Ann Arbor, MI.

[13] Lindberg, P. and Berger, A. (1997), "Continuous improvement - design, organization and management", International Journal of Technology Management, Vol. 14 No. 1, pp. 86-101.

[14] Linderman, K., Schroeder, R., Zaheer, S. and Choo, A. (2003), "Six sigma: a goal - theoretic perspective", Journal of Operations Management, Vol. 21 No. 2, pp. 193-203.

[15] Niven, P. (2002), Balanced Scorecard Step by Step: Maximizing Performance and Maximizing Results, John Wiley \& Sons, New York, NY.

[16] Oakland, J. (1999), Total Organizational Excellence Achieving World-Class Performance,ButterworthHeinemann, Oxford.

[17] Robinson, A. (1990), Modern Approaches to Manufacturing Improvement, Productivity Press, Portland, OR.
[18] Savolainen, T. (1998), "Cycles of continuous improvement, realizing competitive advantages through quality", International Journal of Operations \& Production Management, Vol. 19 No. 11, pp. 1203-22.

[19] Schroeder, D. and Robinson, A. (1991), “America's most successful export to Japan: continuous improvement programs", Sloan Management Review, Vol. 32 No. 3, pp. 67-81.

[20] Tatham, M. and Mackertich, N. (2003), "Is six sigma falling short of expectations", Optimize, pp. 19-21.

[21] Womack, J. and Jones, D. (1996), Lean Thinking, Simon and Schuster, New York, NY.

[22] Womack, J., Jones, D. and Roos, D. (1990), The Machine That Changed the World, Macmillan Publishing, New York, NY.

[23] Gallagher, M., Austin, S. and Caffyn, S. (1997), Continuous Improvement in Action: The Journey of Eight Companies, Kogan Page, London.

[24] Caffyn, S. (1999), "Development of a continuous improvement self- assessment tools", International Journal of Operations \& Production Management, Vol. 19 No. 11, pp. 1138-53.

[25] Bessant, J., Caffyn, S., Gilbert, J., Harding, R. and Webb, S. (1994), "Rediscovering continuous improvement", Technovation, Vol. 14 No. 1, pp. 17-29.

[26] Bessant, J. and Caffyn, S. (1997), "High involvement innovation", International Journal of Technology Management, Vol. 14 No. 1, pp. 7-28.

[27] Berger, A. (1997), "Continuous improvement and kaizen: standardization and organizational designs", Journal of Integrated Manufacturing Systems, Vol. 8 No. 2, pp. 110-7.

[28] Berger, A. (1996), "Perspectives on manufacturing development - discontinuous change and continuous improvement", $\mathrm{PhD}$ thesis, Chalmers University of Technology, Go“teborg. 